\title{
Insight into Podocyte Differentiation from the Study of Human Genetic Disease: Nail-Patella Syndrome and Transcriptional Regulation in Podocytes
}

\author{
ROY MORELLO AND BRENDAN LEE \\ Department of Molecular and Human Genetics, Baylor College of Medicine, Houston, Texas, 77030, U.S.A.
}

\begin{abstract}
ABS
In recent years, our understanding of the molecular basis of
kidney development has benefited from the study of rare genetic
diseases affecting renal function. This has especially been the
case with the differentiation of the highly specialized podocyte in
the pathogenesis of human disorders and mouse phenotypes
affecting the renal filtration barrier. This filtration barrier repre-
sents the end product of a complex series of signaling events that
produce a tripartite structure consisting of interdigitating podo-
cyte foot processes with intervening slit diaphragms, the glomer-
ular basement membrane, and the fenestrated endothelial cell.
Dysregulation of unique cytoskeletal and extracellular matrix
proteins in genetic forms of nephrotic syndrome has shown how
specific structural proteins contribute to podocyte function and
differentiation. However, much less is known about the transcrip-
\end{abstract}
Until recently, much of the study of kidney development has focused on the early inductive events specifying formation of the metanephric kidney. In vertebrate embryogenesis, a primitive nonfunctional kidney rudiment, the pronephros, and a transiently functional mesonephros precede the formation of the permanent metanephric kidney in the fifth week of human development and at E10.5-11 in mouse development. The cells of the excretory and collecting systems derive from mesoderm and undergo a characteristic mesenchymal to epithelial transition superimposed on a process of branching morphogenesis. Multiple molecules, including transcription factors, growth factors, and growth factor receptors, have been identified that regulate the reciprocal inductive interaction between the ureteric bud and metanephric mesenchyme. Several excellent

Received June 8, 2001; accepted November 22, 2001.

Correspondence: Brendan Lee, M.D., Ph.D., Department of Molecular and Human Genetics, Baylor College of Medicine, One Baylor Plaza, Rm 630E, Houston, TX 77030, U.S.A.; e-mail: blee@bcm.tmc.edu

Supported by the Baylor College of Medicine Child Health Research Center and Mental Retardation Research Center, the March of Dimes, and the National Institutes of Health Grants HD22657 and AR44738. R.M. is supported by a fellowship from Telethon-Italy.

Recipient of the Society for Pediatric Research 2000 Young Investigator Award, presented at the 2000 Annual Meeting of the Pediatric Academic Societies, Boston, MA, U.S.A. tional determinants that both specify and maintain this differentiated cell. Our studies of a skeletal malformation syndrome, nail-patella syndrome, have shown how the LIM homeodomain transcription factor, $L m x 1 b$, contributes to transcriptional regulation of glomerular basement membrane collagen expression by podocytes. Moreover, they raise intriguing questions about more global transcriptional regulation of podocyte morphogenesis.

(Pediatr Res 51: 551-558, 2002)

Abbreviations:
Lmx1b, LIM homeodomain transcription factor
NPS, nail-patella syndrome
GBM, glomerular basement membrane

reviews summarize these studies (1-5). These interactions specify the processes of ureteric budding from the mesonephric duct, aggregation of metanephric mesenchyme, its epithelial transformation into glomerular and tubular epithelium, the differentiation into mesangial and stromal cells, and the branching of the ureteric bud to form the collecting duct system. The differentiation of metanephric mesenchyme at the tip of each ureteric bud into the nephron unit traverses morphologically from the renal vesicle, to comma-shaped bodies, to the S-shaped bodies, and, finally, to the epithelialized bodies that become vascularized during glomerular maturation. The end result of these processes is the mature vertebrate kidney with approximately 1.5 million nephron units in humans and 1000-2000 nephron units in mouse (6).

One primary function of the mature vertebrate kidney is filtration of high-molecular-weight proteins present in the blood (not allowing molecules bigger than albumin at $68 \mathrm{kD}$ to cross into urine) (7). This highly specialized function resides in the glomerular filtration unit, composed of 1) fenestrated endothelial cells of the capillary tuft; 2) an intervening GBM, rich in specialized collagens, laminins, and heparin sulfate proteoglycans; and 3) the podocyte, a terminally differentiated visceral glomerular epithelial cell with specialized major cell 
processes and smaller foot processes that extend to interdigitate with adjacent foot processes, forming an intervening slit diaphragm (Fig. 1). Disruption of this unit by environmental, immune, or genetic factors results in loss of the filtration function and, ultimately, some or all features of clinical nephrotic syndrome (8).

The endothelial cell fenestration likely does not contribute greatly to filtration, but the endothelial cell is required for maintenance of the intact unit. From the study of the cloche mutant in zebrafish, it appears that podocyte differentiation can occur independent of endothelial cell differentiation (9). These mutant fish are avascular and, interestingly, podocytes differentiate in the absence of endothelial cells. However, they soon undergo effacement, i.e. fusion of podocyte foot processes with eventual loss of GBM attachment, suggesting that maintenance of normal podocyte morphology and function requires endothelial cell function. The GBM derives initially from fusion of two independent basement membranes, that of developing endothelial cells with that of visceral glomerular epithelial cells. As the visceral glomerular epithelial cell differentiates into the mature podocyte, it continues to add newly synthesized GBM, whereas the contribution of the endothelial cell is thought to cease. Importantly, a developmental switch in the global pattern of GBM matrix expression occurs during glomerulogenesis $(10,11)$. Initially, heterotrimeric type IV collagen containing ubiquitously distributed $\alpha 1$ (IV) and $\alpha 2(\mathrm{IV})$ chains are laid down in GBM. Gradually, during embryogenesis and in postnatal life, it is replaced with heterotrimeric type IV collagen composed of tissue-specific (predominantly in glomeruli) $\alpha 3$ (IV), $\alpha 4($ IV), and $\alpha 5$ (IV) chains. Paralleling this is a developmental switch from heterotrimeric laminin 1, containing $\alpha 1 / \beta 1 / \gamma 1$ chains, to heterotrimeric laminin 11, containing $\alpha 5 / \beta 2 / \gamma 1$, during embryogenesis and postnatal life (12). The importance of these GBM-specific extracellular matrix components for maintenance of an intact filtration unit has been demonstrated by the study of human and mouse models of renal disease. Patients with recessive or X-linked Alport syndrome develop progressive proteinuria due to mutation in either the autosomal 3(IV) and 4(IV) collagen genes (COL4A3 and COLA4), or the X-linked 5(IV) collagen gene (COL4A5) $(13,14)$. Similarly, mouse mutants null for either Col4a3 alone or for both Col4a 3 and Col4a 4 also exhibit phenotypes similar to Alport syndrome in humans, albeit with an earlier onset in the double mutant animals (15-17). Although no human genetic defect of laminin 11 has been reported, mouse mutants null for the laminin $\beta 2$ gene develop nephrosis, in spite of compensation by embryonic laminin $\beta 1$ chain in a morphologically normal GBM (18). Interestingly, in the collagen mutants, laminin isoforms were normally expressed, and, similarly in the laminin mutant, collagen isoforms were normally expressed. Importantly, podocytes differentiated normally in both but showed signs of injury, i.e. fusion of podocyte foot processes. These studies show that these GBM-specific matrix components are required for maintenance of normal podocyte morphology and filtration function, but are not required for podocyte differentiation and foot process formation.

\section{MOLECULAR DETERMINANTS OF PODOCYTE STRUCTURE AND FUNCTION}

The molecular basis for podocyte differentiation has been less well understood compared with the early inductive events of nephrogenesis. However, a better understanding has now been gained from the study of both human and mouse models of renal disease affecting the filtration unit (Table 1) $(8,19,20)$. Podocytes are highly specialized cells with large arborization of cell processes that make up the unique foot processes covering the GBM. Their function is to control the turnover of the GBM and to regulate ultrafiltration of urine. An electrondense slit diaphragm approximately $40 \mathrm{~nm}$ in size extends from foot processes of adjacent cells to form a specialized cell-cell junction $(7,21-23)$. It follows that cytoskeletal components contribute to its differentiation and function. Detailed morphologic studies show that the microtubular cytoskeleton is found in major cell processes whereas actin filaments form the cytoskeleton of the secondary foot processes that extend from the major processes. Alterations in genes that regulate cytoskeletal organization would therefore be expected to affect podocyte differentiation and/or maintenance and hence result in disruption of the filtration barrier. Both congenital and chronic renal diseases resulting from processes such as diabetes and aging are associated with alteration of podocyte integrity often involving effacement of podocyte foot processes, separation from GBM, and/or proliferation of mesangial cells and parietal epithelium $(24,25)$.

An important podocyte component of the slit diaphragm, required for function of the filtration unit, was identified as mutated in congenital nephrotic syndrome of the Finnish type (NPHS1) $(26,27)$. The protein nephrin is a transmembrane adhesion molecule with an extracellular domain containing eight Ig domains and one fibronectin domain. It localizes to the slit diaphragm, which is hypothesized to be formed, in part, by interdigitating nephrin molecules that interact along their Ig domains while extending from opposing foot processes (28, 29). Nephrin null mice exhibit massive proteinuria and neonatal death (30). While podocytes and foot processes form, there are no slit diaphragms and podocyte foot processes quickly undergo effacement. These data show that nephrin is required for slit diaphragm formation and maintenance of podocyte function (31). Studies in mice showed that another protein, the CD2 adaptor protein (Cd2ap), interacts with the intracellular $\mathrm{C}$-terminal domain of nephrin and is required for stabilization of the slit diaphragm (32). Loss of its function in mice causes congenital nephrotic syndrome with podocyte effacement, increased extracellular matrix production, and mesangial cell hyperplasia. Like its role in $\mathrm{T}$ cell-antigen presentation cell signaling, Cd2ap may serve to stabilize specialized cellcell interactions mediated by the Ig family of transmembrane proteins. However, to date, no human condition has yet been associated with Cd2ap mutations. The importance of cytoskeletal organization for podocyte maintenance and foot process formation is further underscored by the finding of mutations in $\alpha$-actinin-4 (ACTN4) in patients with dominantly inherited focal segmental glomerular sclerosis (FSGS1) (33). ACTN4 is an actin filament cross-linking protein that is highly expressed 


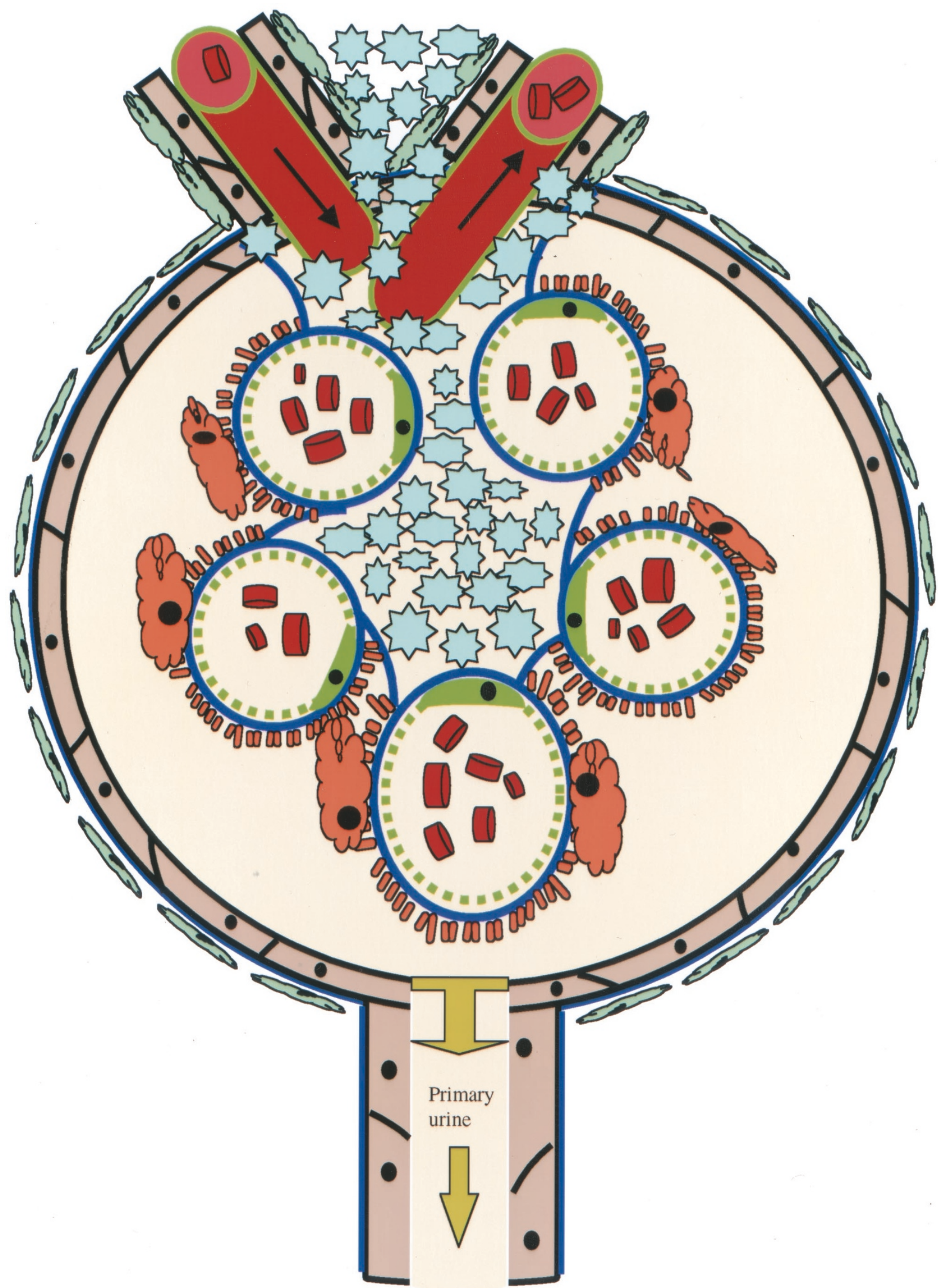

Figure 1. Schematic diagram of the glomerular structure. Orange, podocytes; blue, basement membrane; green, endothelium; red, red blood cells; light blue, mesangial cells. 
Table 1. List of human genetic syndromes associated with nephrosis and their corresponding genetic loci

\begin{tabular}{llll}
\hline \multicolumn{1}{c}{ Locus } & \multicolumn{1}{c}{ Gene } & \multicolumn{1}{c}{ Protein } & \multicolumn{1}{c}{ Disease } \\
\hline Xq22.3 & COL4A5 & COL4A5 & Alport syndrome, X-linked \\
$2 \mathrm{q} 36-\mathrm{q} 37$ & COL4A3-COL4A4 & COL4A3-COL4A4 & Alport syndrome, autosomal recessive \\
$19 \mathrm{q} 13.1$ & NPHS1 & Nephrin & Congenital nephrotic syndrome, Finnish type, autosomal recessive \\
$1 \mathrm{q} 25-\mathrm{q} 31$ & NPHS2 & Podocin & Steroid-resistant nephrotic syndrome, autosomal recessive \\
$9 \mathrm{q} 34$ & LMX1B & LMX1B & NPS, autosomal dominant \\
$19 \mathrm{q} 13$ & $A C T N 4$ & $\alpha-A c t i n i n-4$ & Focal segmental glomerulosclerosis, autosomal dominant \\
$11 \mathrm{p} 13$ & $W T 1$ & WT1 & Denys-Drash syndrome, Frasier syndrome, WAGR syndrome \\
\hline
\end{tabular}

WAGR, Wilms tumor, Aniridia, Genitourinary anomalies, Mental Retardation Syndrome.

in podocytes (34). Interestingly, the FSGS1 mutation caused ACTN4 to bind actin more strongly than wild-type ACTN4, further supporting the critical importance of maintaining normal cytoskeletal homeostasis in podocyte function. Recently, the genetic basis for autosomal recessive steroid-resistant nephrotic syndrome (NPHS2) was identified to be mutations in an integral podocyte membrane protein, podocin (35). Podocin has homology to Caenorhabditis elegans Mec-2. Interestingly, Mec-2 has been implicated in mechanosensation linking the cytoskeleton to ion channels (36). This prompts the question of whether podocin might similarly mediate cytoskeletal-cell membrane communication in podocyte foot processes in response to mechanical forces (37).

A host of podocyte cytoskeletal-associated proteins have been described to date (Fig. 2) (38). These include proteins like P-cadherin, which has been also localized to the slit diaphragm. The slit diaphragm can be viewed as a modified adherens junction between podocytes $(29,39)$. Hence, it is not surprising that zonula occludens protein-1 (ZO1), a multiple-domain membrane-associated signaling protein, has also been localized to the cytoplasmic component of the slit diaphragm (29). GLEPP1 is a single transmembrane protein with an intracellular phosphatase domain and an extracellular domain with eight fibronectin type III repeats. Loss of its function in mice causes decreased GFR and hypertension associated with podocytes with shortened thickened processes $(40-42)$. Synaptopodin is another actin-associated protein found in podocyte foot processes (38). Although no human diseases causing nephrotic syndrome have yet been associated with these molecules, various mouse mutants have highlighted their relevance for podocyte morphogenesis and function. These and other structural components of the podocyte cytoskeleton and slit diaphragm constitute excellent candidates for genetic determinants in the pathogenesis of nephrotic syndrome.

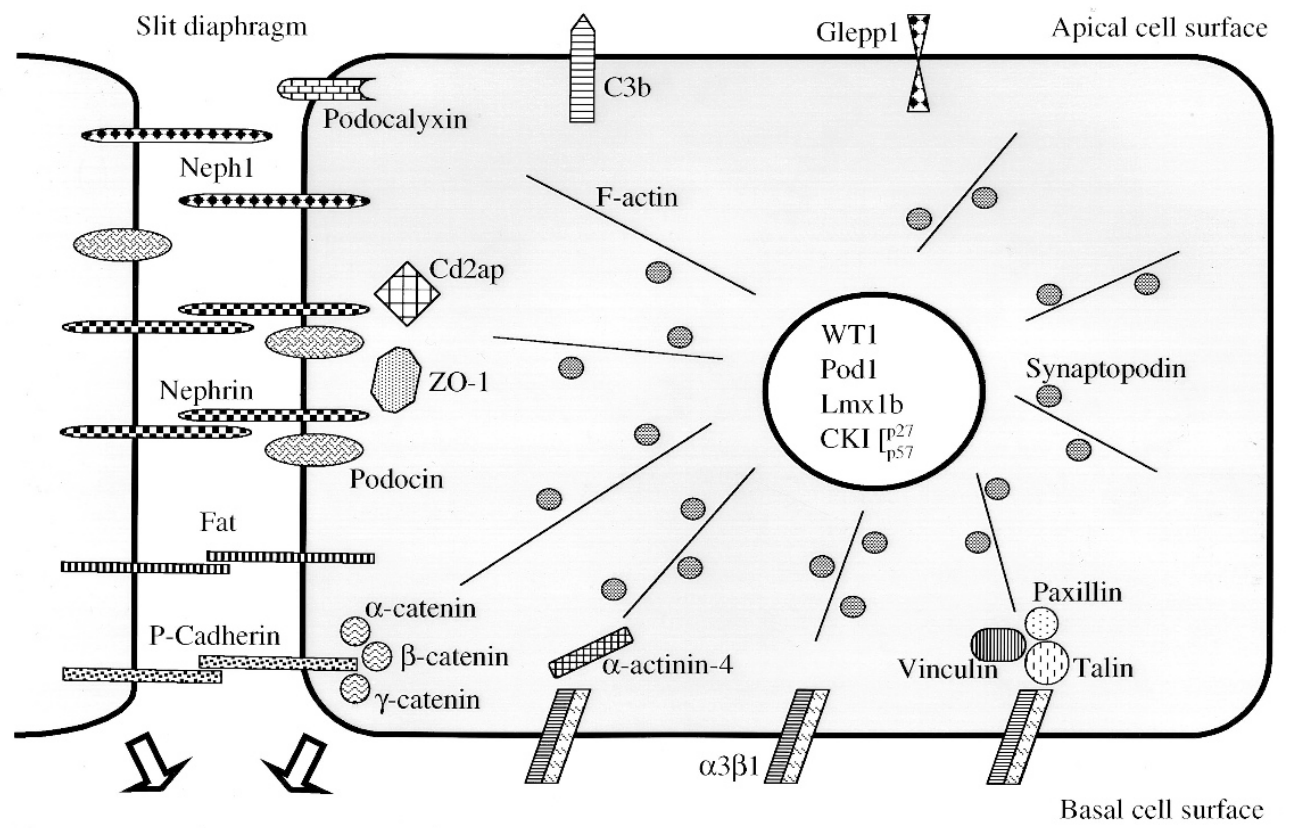

Secreted molecules:

Collagen type IV ( $\alpha 3-\alpha 5)$, Laminin 11, Entactin/Nidogen, Syndecan-4, Glypican, Agrin,

Perlecan, Vegf

Figure 2. Array of genes typically expressed by the mature podocyte. Cell junction and cell junction-associated proteins: nephrin, P-cadherin, Cd2ap, ZO-1; cell adhesion proteins: $\alpha 3 \beta 1$ integrin; focal adhesion proteins: talin, vinculin, paxillin; cytoskeletal associated proteins: $\alpha$-actinin-4, synaptopodin; transmembrane/receptor proteins: podocin, Glepp1, C3b, podocalyxin; transcription factors: WT1, Pod1, Lmx1b; cell cycle-associated proteins: p27, p57; secreted proteins: collagen type $\operatorname{IV}(\alpha 3-\alpha 5)$, laminin 11, entactin/nidogen, syndecan-4, glypican, agrin, perlecan, vascular endothelial growth factor (vegf). 


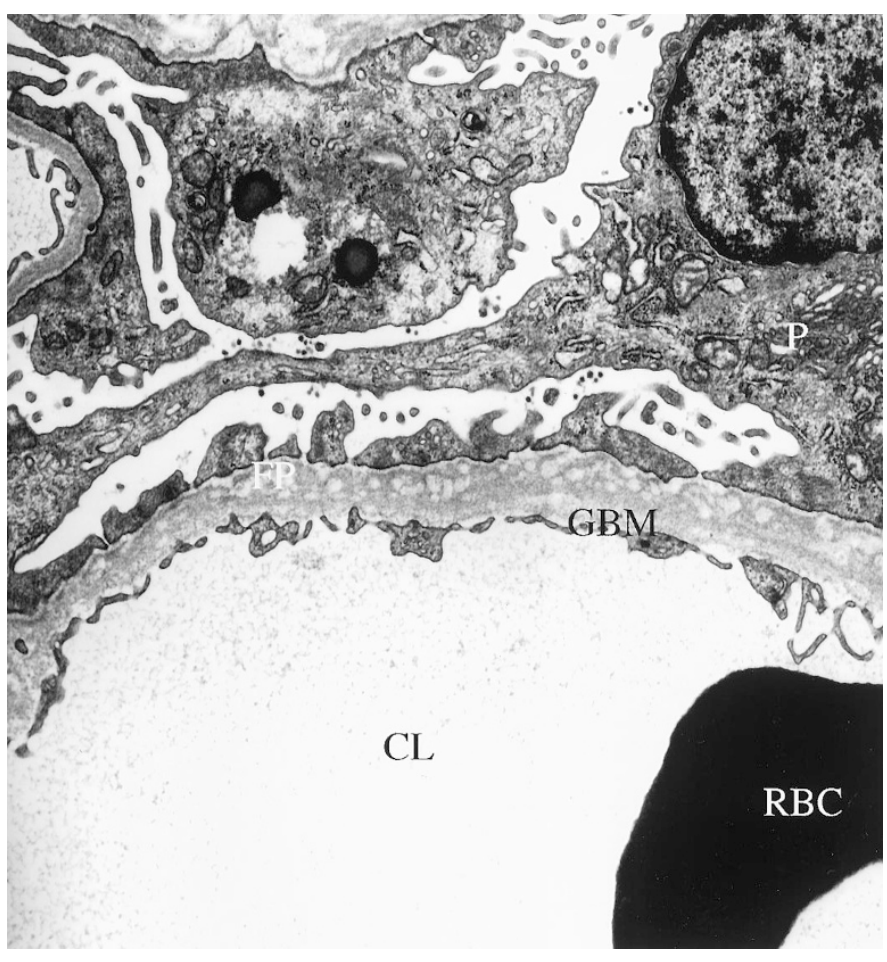

Figure 3. Electron micrograph kidney biopsy from an NPS patient. The patient has a $L m x I b$ mutation (713insA). Thickening of the GBM and fusion of foot processes are observed. $R B C$, red blood cell; $C L$, capillary lumen; $G B M$, glomerular basement membrane; $F P$, foot process; $P$, podocyte.

\section{TRANSCRIPTIONAL REGULATION OF PODOCYTE DIFFERENTIATION}

Transcription factors regulating the specification of early reciprocal induction of ureteric bud and metanephric mesenchyme have been well described. These include Pax2, Lim 1, Eyal, n-Myc1, and Emx2 (5). In contrast to the study of cytoskeletal and architectural proteins specifying podocyte function, few transcriptional regulators of podocyte morphogenesis have been studied either in humans or in mouse models. The Wilms' tumor gene (WT1) is a zinc finger containing transcription factor that acts both early during ureteric bud-metanephric mesenchyme interaction and later during podocyte morphogenesis and maintenance $(19,43)$. Although loss of its function places patients at risk for development of Wilms' tumor, subtle mutations may produce congenital malformation of the urogenital system observed in Denys-Drash syndrome and Frasier syndrome (44). The former is characterized by diffuse mesangial sclerosis, male-pseudohermaphroditism, and Wilms' tumor. It is thought to arise from dominant negative action. The latter is associated with severe nephrotic syndrome, gonadal dysgenesis, and risk of developing gonadal tumors, especially gonadoblastoma. Renal biopsy in these patients often shows focal segmental glomerular sclerosis and the phenotype is thought to be the result of alteration of the dosage ratio between alternatively spliced WT1 isoforms. Interestingly, children with diffuse mesangial sclerosis without evidence of Denys-Drash syndrome have been found to harbor mutations in WT1 (45). Clearly, WT1 functions early during metanephric kidney development and then later during podo- cyte morphogenesis. Heterozygous germline loss of function can result in tumorigenesis when associated with somatic mutation of the other allele, whereas the genitourinary phenotype marked by early nephrotic syndrome is associated with dominant mutations with incomplete penetrance. The downstream targets, however, are poorly characterized and the relationship of WT1 to the architectural proteins that specify the podocyte phenotype is still unknown.

\section{NPS AND PODOCYTE FUNCTION}

Insight into an important transcriptional regulator of podocyte function has recently been gained from the study of a human skeletal malformation syndrome, NPS. NPS is a dominantly inherited skeletal dysplasia characterized by hypoplasia of nails and patella, joint abnormalities, iliac horns, and nephropathy (46). Although only approximately $30-40 \%$ of patients have clinical nephropathy, histopathologic changes in the kidney have been reported even in fetal cases of NPS (47, 48). We and others have shown that NPS is caused by heterozygous mutations in the LIM homeodomain transcription factor $L M X 1 B$ (49-55). LIM domains are zinc fingercontaining motifs that have been found in over 40 different proteins. The LIM domain mediates protein-protein interactions and has been implicated in diverse biologic processes (56, 57). LIM homeodomain transcription factors compose a large family with over nine members and have been shown to be of critical importance in cell type differentiation, including pituitary gland differentiation (58). Lmxlb is a LIM homeodomain transcription factor originally described in chick as being required for dorsoventral pattern formation during limb development (59). Lmxlb expression during mouse limb development initially localizes to dorsal limb bud mesenchyme at E10.5. It continues to be highly expressed in dorsal mesenchyme until E16.5. This expression pattern predicts the consequences of loss of function in humans, i.e. dysplasia of dorsal mesenchyme-derived tissues, including nails and patella, and joint anomalies $(60,61)$. However, the observation of renal dysplasia in NPS pointed to a previously unrecognized function for $L m x l b$ during renal development. Lmxlb expression begins early in the S-shaped bodies, and, in contrast to its transient expression in the limb, expression in the kidneys continues postnatally in visceral glomerular epithelium (60, 62).

NPS patients have characteristic histologic findings on renal biopsy including thickened and split GBM and fusion of podocyte foot processes (Fig. 3). Interestingly, Lmxlb heterozygote mice have normal-appearing glomeruli at both the light and ultrastructural levels (data not shown). In contrast, $L m \times 1 b$ null mice die shortly after birth and have severe renal abnormalities, including smaller kidneys and tubules distended with periodic acid-Schiff positive staining material consistent with severe proteinuria (60). Importantly, glomeruli are normally formed and podocytes normally express nephrin. However, glomeruli show GBM alterations similar to that observed in NPS as well as podocytes with ultrastructural features of arrested development $(60,62)$. The GBM alterations raised the question of whether Lmxlb might regulate structural compo- 
A
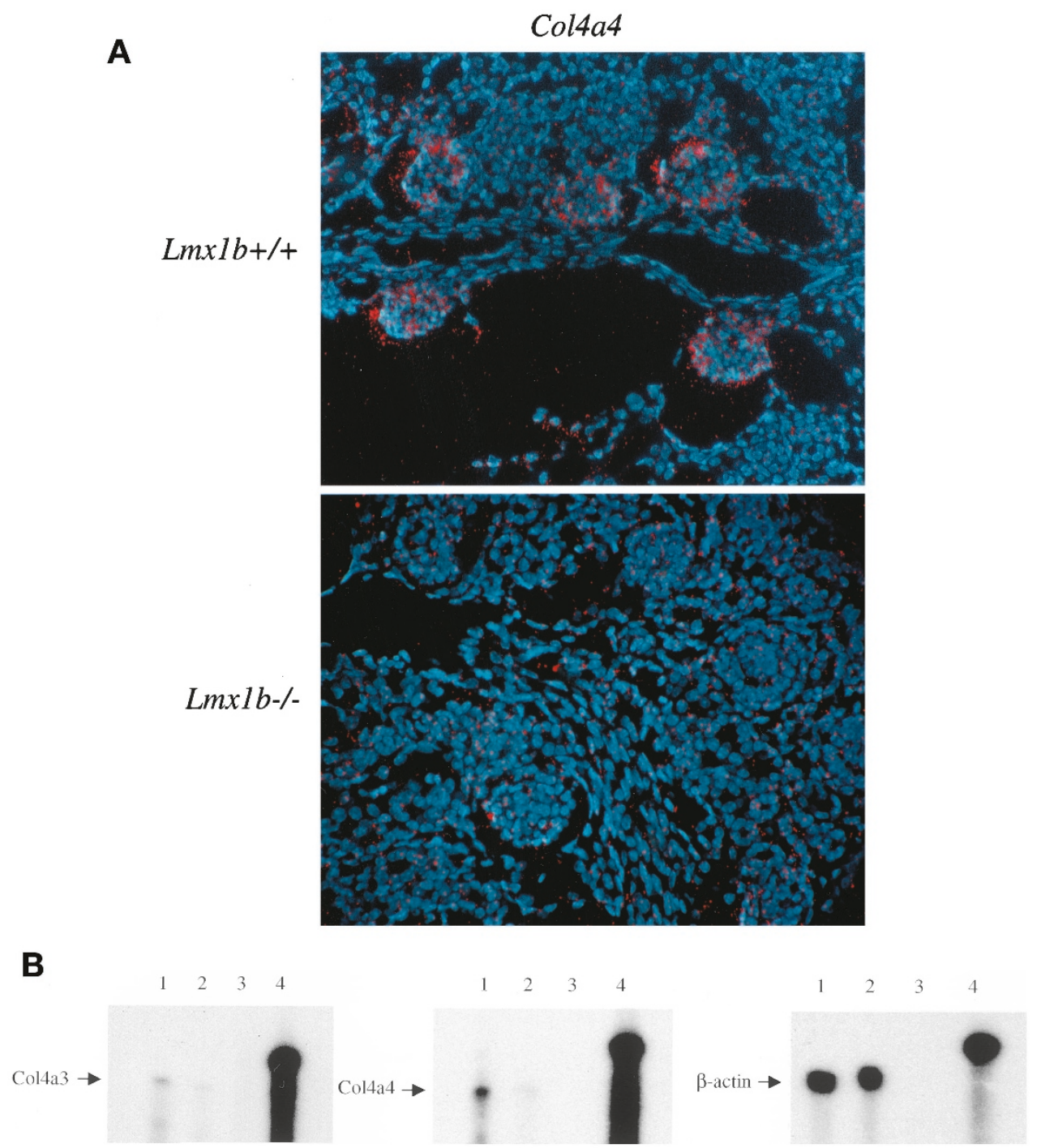

Figure 4. (B) In situ hybridization assay using a riboprobe specific for Col4a4 of newborn kidney sections from wild-type and $L m x 1 b-/-$ mutant mice. Expression of $\alpha 4$ (IV) collagen is almost absent in the mutant kidney compared with its wild-type counterpart. (B) Ribonuclease protection assay of kidney RNA derived from $L m x 1 b$ mutant kidneys using Col4a3 and Col4a4 probes. Lane 1: wild-type kidney total RNA; lane 2: Lmxlb mutant kidney total RNA; lane 3: yeast RNA; lane 4: RNase negative control. Left panel, center panel, and right panel show experiments with Col4a3, Col4a4 and $\beta$-actin-specific probes, respectively. An equal amount of total RNA has been used in lanes 1 and 2. Protected fragments corresponds to detectable level of expression in wild-type kidneys, whereas decrease in the protected fragment corresponds to much decreased expression of Col4a4 and some decrease in Col4a3 mRNA in mutant kidneys.

nents of GBM on a transcriptional level. We have found that Col4a1 and Col4a2 expression was comparable in $L m x 1 b$ wild-type and null mice (62). In contrast, expression of kidney-specific Col4a3 and Col4a4 was dramatically decreased at both protein and mRNA levels (Fig. 4). This suggested that $L m x 1 b$ is required for expression of Col4a 3 and Col4a 4 and the developmental switch from the ubiquitous basement membrane collagens to the GBM-specific isoforms. The tandem genomic organization of Col4a3 and Col4a4 (63) suggested that Lmxlb might direct transcriptional regulation of this locus and loss of their expression is not a secondary effect. In fact, within an otherwise poorly conserved Col4a 4 intron 1 sequence, we have identified a conserved LMX1B binding site at its 3 ' end (62). Together, the data suggest that Lmxlb may serve as a transcriptional activator required for coordinate expression of Col4a3 and
Col4a4, making it a key transcriptional determinant of GBM formation. These data beg the question of whether it might directly regulate the developmental switch in matrix expression. Although $L m x l b$ is required for collagen expression, it is likely not sufficient to specify the switch, inasmuch as we have found that laminin $\beta 1$ and laminin $\beta 2$ expression is unchanged in Lmxlb null mice kidneys (data not shown). However, the phenotypic severity of the null mice suggests that $L m x 1 b$ must regulate other genes required for podocyte function. The nephropathy in $L m x 1 b$ null mice is histologically more severe and of earlier onset than that observed in the Col4a 3 or double Col4a3/Col4a 4 mouse mutants (15, 16). Hence, loss of $\alpha 3$ (IV) and $\alpha 4$ (IV) collagen chains alone cannot account for the full renal phenotype and it is likely that $L m x l b$ regulates additional genes that contribute to podocyte function and maintenance. Candidate genes in- 
clude cytoskeletal and architectural genes such as podocin, synaptopodin, Cd2ap, ZO1, etc.

The analysis of the expression of these genes in $L m x 1 b$ null mice and the search for potential LMX1B binding sites in their respective promoters will help to determine whether they are members of the list of $L m x 1 b$ targets that account for its role in podocyte differentiation. Other critical questions remain about the role of $L m x l b$ regulation in podocyte differentiation: What transcription factors regulate and cooperate with $L m x 1 b$ function? It is likely that $L m x l b$ functions in different development pathways in a context-dependent and organ-specific fashion and is, in part, dictated by different combinations of proteins that interact with it. For example, the closely related LIM homeodomain transcription factor Lmxla has been described as transactivating the insulin promoter cooperatively with a helix-loop-helix transcription factor E47 (64). Interestingly, another helix-loop-helix protein, Pod1/capsulin/TCF21, is specifically expressed in S-shaped bodies and continues to be expressed in maturing podocytes, paralleling the expression pattern of $L m x 1 b$ (65). Loss of its function results in hypoplastic lungs and kidneys that lack mature glomeruli or nephrons (66). It will be important to determine whether Podl might interact with $L m x 1 b$ to coordinately regulate the collection of architectural genes that define podocyte differentiation and function.

The study of $L m x l b$ in NPS has shown that it is required for basement membrane collagen expression. Moreover, the severity of the mouse phenotype suggests that loss of additional podocyte genes accounts for arrested podocyte differentiation. Candidate targets for $L m x 1 b$ include multiple cytoskeletal and integral membrane proteins important for podocyte differentiation and maintenance. Elucidating the potential interaction of $L m x l b$ with the few other transcription factors identified in podocyte function, including $W T 1$ and Pod1, will be important in understanding the transcriptional network coordinating podocyte differentiation. Ultimately, this will impact on our understanding of diseases characterized by nephrotic syndrome and on the development of restorative strategies for these disease processes.

Acknowledgments. The authors thank J. Miner for helpful discussions and $\mathrm{O}$. Hernandez for administrative assistance.

\section{REFERENCES}

1. Lechner MS, Dressler GR 1997 The molecular basis of embryonic kidney development. Mech Dev 62:105-120

2. Vainio S, Muller U 1997 Inductive tissue interactions, cell signaling, and the control of kidney organogenesis. Cell 90:975-978

3. Kuure S, Vuolteenaho R, Vainio S 2000 Kidney morphogenesis: cellular and molecular regulation. Mech Dev 92:31-45

4. Dressler GR 1999 Kidney development branches out. Dev Genet 24:189-193

5. Burrow CR 2000 Regulatory molecules in kidney development. Pediatr Nephrol $14: 240-253$

6. Davies JA, Bard JB 1998 The development of the kidney. Curr Top Dev Biol 39:245-301

7. Abrahamson DR 1987 Structure and development of the glomerular capillary wall and basement membrane. Am J Physiol 253:F783-F794

8. Piscione TD, Rosenblum ND 1999 The malformed kidney: disruption of glomerular and tubular development. Clin Genet 56:341-356

9. Majumdar A, Drummond IA 1999 Podocyte differentiation in the absence of endothelial cells as revealed in the zebrafish avascular mutant, cloche. Dev Genet $24: 220-229$
10. Miner JH, Sanes JR 1994 Collagen IV alpha 3, alpha 4, and alpha 5 chains in rodent basal laminae: sequence, distribution, association with laminins, and developmental switches. J Cell Biol 127:879-891

11. Harvey SJ, Zheng K, Sado Y, Naito I, Ninomiya Y, Jacobs RM, Hudson BG, Thorner PS 1998 Role of distinct type IV collagen networks in glomerular development and function. Kidney Int 54:1857-1866

12. Miner JH, Patton BL, Lentz SI, Gilbert DJ, Snider WD, Jenkins NA, Copeland NG, Sanes JR 1997 The laminin alpha chains: expression, developmental transitions, and chromosomal locations of alpha1-5, identification of heterotrimeric laminins 8-11, and cloning of a novel alpha3 isoform. J Cell Biol. 1997 137:685-701

13. Hudson BG, Reeders ST, Tryggvason K 1993 Type IV collagen: structure, gene organization, and role in human diseases. Molecular basis of Goodpasture and Alport syndromes and diffuse leiomyomatosis. J Biol Chem 268:26033-26036

14. Sado Y, Kagawa M, Naito I, Ueki Y, Seki T, Momota R, Oohashi T, Ninomiya Y 1998 Organization and expression of basement membrane collagen IV genes and their roles in human disorders. J Biochem (Tokyo) 123:767-776

15. Cosgrove D, Meehan DT, Grunkemeyer JA, Kornak JM, Sayers R, Hunter WJ, Samuelson GC 1996 Collagen COL4A3 knockout: a mouse model for autosomal Alport syndrome. Genes Dev 10:2981-2992

16. Lu W, Phillips CL, Killen PD, Hlaing T, Harrison WR, Elder FF, Miner JH, Overbeek $\mathrm{PA}$, Meisler MH 1999 Insertional mutation of the collagen genes Col4a3 and Col4a4 in a mouse model of Alport syndrome. Genomics 61:113-124

17. Miner JH, Sanes JR 1996 Molecular and functional defects in kidneys of mice lacking collagen alpha 3(IV): implications for Alport syndrome. J Cell Biol 135:1403-1413

18. Noakes PG, Miner JH, Gautam M, Cunningham JM, Sanes JR, Merlie JP 1995 The renal glomerulus of mice lacking s-laminin/laminin beta 2: nephrosis despite molecular compensation by laminin beta 1 . Nat Genet 10:400-406

19. Bates CM 2000 Kidney development: regulatory molecules crucial to both mice and men. Mol Genet Metab 71:391-396

20. Smoyer WE, Mundel P 1998 Regulation of podocyte structure during the development of nephrotic syndrome. J Mol Med 76:172-183

21. Hyodo T, Naguro T, Kameie T, Iino A, Miyagawa I 1997 Scanning and transmission electron-microscopic study of the development of the podocyte in the human fetus. Pediatr Nephrol 11:133-139

22. Mundel P, Shankland SJ 1999 Glomerular podocytes and adhesive interaction with glomerular basement membrane. Exp Nephrol 7:160-166

23. Nagata M, Nakayama K, Terada Y, Hoshi S, Watanabe T 1998 Cell cycle regulation and differentiation in the human podocyte lineage. Am J Pathol 153:1511-1520

24. Pavenstadt H 2000 Roles of the podocyte in glomerular function. Am J Physiol Renal Physiol 278:F173-F179

25. Kriz W, Lemley KV 1999 The role of the podocyte in glomerulosclerosis. Curr Opin Nephrol Hypertens 8:489-497

26. Kestila M, Lenkkeri U, Mannikko M, Lamerdin J, McCready P, Putaala H, Ruotsalainen V, Morita T, Nissinen M, Herva R, Kashtan CE, Peltonen L, Holmberg C, Olsen A, Tryggvason K 1998 Positionally cloned gene for a novel glomerular protein - nephrin - is mutated in congenital nephrotic syndrome. Mol Cell 1:575-582

27. Lenkkeri U, Mannikko M, McCready P, Lamerdin J, Gribouval O, Niaudet PM, Antignac C K, Kashtan CE, Homberg C, Olsen A, Kestila M, Tryggvason K 1999 Structure of the gene for congenital nephrotic syndrome of the finnish type (NPHS1) and characterization of mutations. Am J Hum Genet 64:51-61

28. Ruotsalainen V, Ljungberg P, Wartiovaara J, Lenkkeri U, Kestila M, Jalanko H, Holmberg C, Tryggvason K 1999 Nephrin is specifically located at the slit diaphragm of glomerular podocytes. Proc Natl Acad Sci U S A 96:7962-7967

29. Ruotsalainen V, Patrakka J, Tissari P, Reponen P, Hess M, Kestila M, Holmberg C, Salonen R, Heikinheimo M, Wartiovaara J, Tryggvason K, Jalanko H 2000 Role of nephrin in cell junction formation in human nephrogenesis. Am J Pathol 157:19051916

30. Putaala H, Soininen R, Kilpelainen P, Wartiovaara J, Tryggvason K 2001 The murine nephrin gene is specifically expressed in kidney, brain and pancreas: inactivation of the gene leads to massive proteinuria and neonatal death. Hum Mol Genet 10:1-8

31. Tryggvason K 1999 Unraveling the mechanisms of glomerular ultrafiltration: nephrin, a key component of the slit diaphragm. J Am Soc Nephrol 10:2440-2445

32. Shih NY, Li J, Karpitskii V, Nguyen A, Dustin ML, Kanagawa O, Miner JH, Shaw AS 1999 Congenital nephrotic syndrome in mice lacking CD2-associated protein. Science 286:312-315

33. Kaplan JM, Kim SH, North KN, Rennke H, Correia LA, Tong HQ, Mathis BJ, Rodriguez-Perez JC, Allen PG, Beggs AH, Pollak MR 2000 Mutations in ACTN4, encoding alpha-actinin-4, cause familial focal segmental glomerulosclerosis. Nat Genet 24:251-256

34. Lachapelle M, Bendayan M 1991 Contractile proteins in podocytes: immunocytochemical localization of actin and alpha-actinin in normal and nephrotic rat kidneys. Virchows Arch B Cell Pathol Incl Mol Pathol 60:105-111

35. Boute N, Gribouval O, Roselli S, Benessy F, Lee H, Fuchshuber A, Dahan K, Gubler MC, Niaudet P, Antignac C 2000 NPHS2, encoding the glomerular protein podocin, is mutated in autosomal recessive steroid-resistant nephrotic syndrome. Nat Genet 24:349-354

36. Mannsfeldt AG, Carroll P, Stucky CL, Lewin GR 1999 Stomatin, a MEC-2 like protein, is expressed by mammalian sensory neurons. Mol Cell Neurosci 13:391-404

37. Endlich N, Kress KR, Reiser J, Uttenweiler D, Kriz W, Mundel P, Endlich K 2001 Podocytes respond to mechanical stress in vitro. J Am Soc Nephrol 12:413-422

38. Mundel P, Heid HW, Mundel TM, Kruger M, Reiser J, Kriz W 1997 Synaptopodin: an actin-associated protein in telencephalic dendrites and renal podocytes. J Cell Biol 139:193-204

39. Reiser J, Kriz W, Kretzler M, Mundel P 2000 The glomerular slit diaphragm is a modified adherens junction. J Am Soc Nephrol 11:1-8 
40. Wharram BL, Goyal M, Gillespie PJ, Wiggins JE, Kershaw DB, Holzman LB, Dysko RC, Saunders TL, Samuelson LC, Wiggins RC 2000 Altered podocyte structure in GLEPP1 (Ptpro)-deficient mice associated with hypertension and low glomerular filtration rate. J Clin Invest 106:1281-1290

41. Thomas PE, Wharram BL, Goyal M, Wiggins JE, Holzman LB, Wiggins RC 1994 GLEPP1, a renal glomerular epithelial cell (podocyte) membrane protein - tyrosine phosphatase. Identification, molecular cloning, and characterization in rabbit. J Biol Chem 269:19953-19962

42. Wiggins RC, Wiggins JE, Goyal M, Wharram BL, Thomas PE 1995 Molecular cloning of cDNAs encoding human GLEPP1, a membrane protein tyrosine phosphatase: characterization of the GLEPP1 protein distribution in human kidney and assignment of the GLEPP1 gene to human chromosome 12p12-p13. Genomics 27:174-181

43. Pritchard-Jones K 1999 The Wilms tumour gene, WT1, in normal and abnormal nephrogenesis. Pediatr Nephrol 13:620-625

44. McTaggart SJ, Algar E, Chow CW, Powell HR, Jones CL 2001 Clinical spectrum of Denys-Drash and Frasier syndrome. Pediatr Nephrol 16:335-339

45. Jeanpierre C, Denamur E, Henry I, Cabanis MO, Luce S, Cecille A, Elion J, Peuchmaur M, Loirat C, Niaudet P, Gubler MC, Junien C 1998 Identification of constitutional WT1 mutations, in patients with isolated diffuse mesangial sclerosis, and analysis of genotype/phenotype correlations by use of a computerized mutation database. Am J Hum Genet 62:824-33

46. Jones KL 1997 Nail-patella syndrome. In: Smith's Recognizable Patterns of Human Malformation. WB Saunders, Philadelphia, pp 438-439

47. Taguchi T, Takebayashi S, Nishimura M, Tsuru N 1988 Nephropathy of nail-patella syndrome. Ultrastruct Pathol 12:175-183

48. Drut RM, Chandra S, Latorraca R, Gilbert-Barness E 1992 Nail-patella syndrome in a spontaneously aborted 18-week fetus: ultrastructural and immunofluorescent study of the kidneys. Am J Med Genet 43:693-696

49. Dreyer SD, Zhou G, Baldini A, Winterpacht A, Zabel B, Cole W, Johnson RL, Lee B 1998 Mutations in LMX1B cause abnormal skeletal patterning and renal dysplasia in nail patella syndrome. Nat Genet 19:47-50

50. McIntosh I, Dreyer SD, Clough MV, Dunston JA, Eyaid W, Roig CM, Montgomery T, Ala-Mello S, Kaitila I, Winterpacht A, Zabel B, Frydman M, Cole WG, Francomano CA, Lee B 1998 Mutation analysis of LMX1B gene in nail-patella syndrome patients. Am J Hum Genet 63:1651-1658

51. Vollrath D, Jaramillo-Babb VL, Clough MV, McIntosh I, Scott KM, Lichter PR, Richards JE 1998 Loss-of-function mutations in the LIM-homeodomain gene, LMX1B, in nail-patella syndrome. Hum Mol Genet 7:1091-1098

52. Clough MV, Hamlington JD, McIntosh I 1999 Restricted distribution of loss-offunction mutations within the LMX1B genes of nail-patella syndrome patients. Hum Mutat 14:459-465
53. Seri M, Melchionda S, Dreyer S, Marini M, Carella M, Cusano R, Piemontese MR, Caroli F, Silengo M, Zelante L, Romeo G, Ravazzolo R, Gasparini P, Lee B 1999 Identification of LMX1B gene point mutations in Italian patients affected with nail-patella syndrome. Int J Mol Med 4:285-290

54. Knoers NV, Bongers EM, van Beersum SE, Lommen EJ, van Bokhoven H, Hol FA 2000 Nail-patella syndrome: identification of mutations in the LMX1B gene in Dutch families. J Am Soc Nephrol 11:1762-1766

55. Hamlington JD, Clough MV, Dunston JA, McIntosh I 2000 Deletion of a branchpoint consensus sequence in the LMX1B gene causes exon skipping in a family with nail patella syndrome. Eur J Hum Genet 8:311-314

56. Dawid IB, Breen JJ, Toyama R 1998 LIM Domains - multiple roles as adapters and functional modifiers in protein interactions. Trends Genet 14:156-162

57. Bach I 2000 The LIM domain: regulation by association. Mech Dev 91:5-17

58. Hobert O, Westphal H 2000 Functions of LIM-homeobox genes. Trends Genet $16: 75-83$

59. Riddle RD, Ensini M, Nelson C, Tsuchida T, Jessell TM, Tabin C 1995 Induction of the LIM homeobox gene Lmx1 by WNT7a establishes dorsoventral pattern in the vertebrate limb. Cell 83:631-640

60. Chen H, Lun Y, Ovchinnikov D, Kokubo H, Oberg KC, Pepicelli CV, Gan L, Lee B, Johnson RL 1998 Limb and kidney defects in Lmx1b mutant mice suggest an involvement of Lmxlb in human nail patella syndrome. Nat Genet 19:5155

61. Dreyer SD, Morello R, German MS, Zabel B, Winterpacht A, Lunstrum GP, Horton WA Oberg KC, Lee B 2000 LMX1B transactivation and expression in nail-patella syndrome. Hum Mol Genet 9:1067-1074

62. Morello R, Zhou G, Dreyer SD, Harvey SJ, Ninomiya Y, Thorner PS, Miner JH, Cole W, Winterpacht A, Zabel B, Oberg KC, Lee B 2001 Regulation of glomerular basement membrane collagen expression by LMX1B contributes to renal disease in nail patella syndrome. Nat Genet 27:205-208

63. Momota R, Sugimoto M, Oohashi T, Kigasawa K, Yoshioka H, Ninomiya Y 1998 Two genes, COL4A3 and COL4A4 coding for the human alpha3(IV) and alpha4(IV) collagen chains are arranged head-to-head on chromosome 2q36. FEBS Lett 424:11-16

64. Johnson JD, Zhang W, Rudnick A, Rutter WJ, German MS 1997 Transcriptional synergy between LIM-homeodomain proteins and basic helix-loop-helix proteins: the LIM2 domain determines specificity. Mol Cell Biol 17:3488-3496

65. Quaggin SE, Vanden Heuvel GB, Igarash P 1998 Pod-1, a mesoderm-specific basic-helix-loop-helix protein expressed in mesenchymal and glomerular epithelial cells in the developing kidney. Mech Dev 71:37-48

66. Quaggin SE, Schwartz L, Cui S, Igarashi P, Deimling J, Post M, Rossant J 1999 The basic-helix-loop-helix protein pod1 is critically important for kidney and lung organogenesis. Development 126:5771-5783 